\title{
Creating an Inclusive Ecosystem through Professional Development
}

\section{Dr. Edward Pines, New Mexico State University}

Edward Pines is Department Head and Associate Professor of Industrial Engineering at New Mexico State University. He is a co-team leader of NMSU's Pathways to Innovation team and is serves on the Faculty Advisory Board for NMSU Engineering's Aggie Innovation Space.

\section{Dr. Patricia A. Sullivan, New Mexico State University}

Patricia A. Sullivan serves as Associate Dean for Outreach and Public Service and is Director of the Engineering New Mexico Resource Network in the College of Engineering at New Mexico State University. She received her $\mathrm{PhD}$ in industrial engineering and has over 31 years' experience directing statewide engineering outreach services that include technical engineering business assistance, professional development, and educational outreach programs. She is co-PI for a National Science Foundation (NSF) grant to broaden participation among minority engineering students through engagement in innovation and entrepreneurship and a co-PI for an i6 Challenge grant through the U.S. Economic Development Administration (EDA) to foster regional economic development through innovation and new business start-ups. She is institutional integrator for the Partnership for the Advancement of Engineering Education (PACE) at NMSU. She is also co-lead for a NSF funded Pathways to Innovation cohort at NMSU with a focus on integrating innovation and entrepreneurship into the engineering curriculum through a blending of industry and educational experiences. Patricia serves as a commissioner for the Western Interstate Commission for Higher Education (WICHE), is a member of the executive committee for the NM Consortia for Energy Workforce Development, a past member of the board of directors for BEST Robotics Inc., and a member of the board of directors for Enchantment Land Certified Development Company (ELCDC - a program that certifies SBA 504 loans that foster economic development.) She has extensive experience in pubic-private partnerships particularly efforts that enhance employment opportunities for engineering students. 


\title{
Creating an Inclusive Ecosystem through Professional Development
}

\begin{abstract}
An inclusive ecosystem within engineering education has been developed, having evolved around a series of stratified professional development courses spanning working professionals, university faculty, and university students. This ecosystem has allowed us to engage industry partners in the academic enterprise, fostered an environment for faculty renewal, and consequently created a venue for engagement of an ethnically diverse student populace from disparate economic backgrounds.
\end{abstract}

It is widely accepted that professional development education conforms to a different teaching model than that of traditional higher education. Engineering faculty often view the value proposition of teaching professional development-type courses to industry professionals as being in conflict with promotion and tenure. Yet, the connections to industry provided through professional development education cannot be easily put aside. Specifically, the applied focus of professional development education affords engineering faculty a unique opportunity to transcend traditional theory-based teaching, bringing relevancy and application directly into the classroom.

Professional development courses for undergraduates, taught by both engineering faculty and industry professionals are also emerging. Offered as non-credit pop-up sessions, these workshops are providing undergraduate students with skills to readily traverse multi-disciplinary projects through venues that bridge engineering concepts and theory with application.

Three years into development of our ecosystem, we continue to engage stakeholders at the campus level and across the broader industry-based community to expand our professional development offerings at various levels. Industry partners have proven to be key contributors in growing the ecosystem, bringing financial support, project expertise, and, coupled with faculty buy-in, legitimacy to our efforts. In this paper, we offer requirements for an effective partnership, some dos and don'ts, the evolution of a business model to support a sustainable funding mechanism, and some accomplishments.

Introduction

America must ensure that our citizens have access to high quality and affordable educational, learning, and training opportunities throughout their lives. ${ }^{1}$ Today's students and tomorrow's graduates are likely to value access to lifelong learning opportunities more highly than job security, which will be elusive in any event. They understand that in the turbulent world of a knowledge economy, characterized by outsourcing and offshoring to a global workforce, employees are only one paycheck away from the unemployment line unless they commit to continuous learning and re-skilling to adapt to changing work requirements. ${ }^{2}$

One vision of the evolving need for continuous engineering education would be the creation of a seamless value chain in which a college of engineering would coordinate activities that benefit students from age 5 to 105 . In such a value chain, alumni and other area technical professionals 
would have access to non-credit opportunities for professional development that local, regional and other employers actively support. Through such an inclusive ecosystem, we could deploy a metaphor of a system of systems of value-added activities that supports learning among K-12, college, graduate school, and engineering professionals. A university's college of engineering can create a unique role for itself by brokering such activities. In this role, the need for market feedback for process improvement could become a norm.

Professional development education requires a different business model than that of traditional undergraduate and graduate education. Topics are different, students engage differently in the learning process, and an understanding of evolving workforce needs by faculty is paramount. Early career faculty members adapting to traditional teaching norms may find professional development courses in conflict with the world of tenure-track faculty. Some more experienced faculty members, particularly among land-grant institutions whose mission includes service to the broader community, may be more inclined to espouse the value of continuous learning. The transition from theory-based education to professional development is unique. There are numerous differences or discontinuities between the learning environments of the university or college and the world of work. ${ }^{3}$ Thus, the ability to organize faculty and industry in an effort to make professional development easily available and cost-effective can be a benefit for all and should not be easily put aside. Thus, as we encourage participation in professional engineering education, we encourage faculty growth at the same time.

The question of how best to organize an inclusive ecosystem to meet such challenges and deliver reliable and effective programs emerges from the background of such discussions. Through creation of the Engineering New Mexico Resource Network, the College of Engineering at New Mexico State University sought to create a service entity within the traditional academic structure. This entity was charged with envisioning outreach efforts and coordinating the delivery of programs including professional development to professional engineers, K-12 teachers, and other professionals. In doing so, new ventures leveraged existing resources and a consistent and inclusive brand identity emerged.

Development and Emergence of Inclusive Ecosystem

The evolving nature of today's workforce makes professional development even more necessary and relevant than ever. Through inclusive partnerships with industry, higher education institutions are creating mutually beneficial relationships to train and retrain the workforce.

The engineering workforce of tomorrow, and indeed that of today, will face profound new challenges. Every day the men and women of this workforce will face the stress of competing in the fast-paced world of change called the knowledge-based global economy. They will also face even larger challenges because the nation and world will need to call on them to seize opportunities and solve global problems of unprecedented scope and scale. ${ }^{4}$

In view of the broadening and rapidly shifting scope of the engineering profession, it is imperative to shift the focus of engineering curricula from transmission of content to development of skills that support engineering thinking and professional judgment. Future engineers will need to adapt to rapidly changing work environments and technology, direct their 
own learning, broaden an understanding of impact, work across different perspectives, and continually revisit what it means to be an engineer. ${ }^{5}$

Coupled with a changing workforce, many organizations are moving away from general research and development (R\&D) and are focusing more narrowly on specific needs. This short-term focus has the potential to lead to a decline in long-term innovation. Colleges and universities can supplement the longer-term innovation research by keeping industries up-to-date with "the frontiers of research" that the industry partner may not have resources on which to specifically focus. ${ }^{6}$ Professional development offers a logical venue for transferring this knowledge directly into the workforce with industry partners benefiting from faculty expertise realized through faculty research in relevant topical areas.

\section{Requirements for an effective partnership}

The shift to today's knowledge-based economy has also brought about a shift in industryuniversity (I/U) relationships from "sponsorship" to "partnership," with ongoing interaction the major focus. ${ }^{7}$ No entity has the advantage of endless resources of people and funds. A 2006 study by Prigge notes that mutually beneficial relationships with industry requires that universities proactively manage their relationship with industry, putting processes and organizational structures in place to reduce or eliminate risks while maximizing the benefits to both industry and themselves. ${ }^{8}$

An inclusive strategy was required to leverage industry relationships with workforce needs for the benefit of current and potential constituents. In the creation of our ecosystem, we identified the following as requirements for effective partnerships: (1) alignment of I/U topical area interests, (2) engagement of K-12 educational system, (3) commitment to educating a diverse engineering workforce, and (4) affordable delivery of professional development courses.

Initially, collaborative relationships, spanning research to professional development, were developed with a number of industry partners with existing recruitment relationships with the college. These relationships were leveraged with broader collaboration with the respective industry associations. Further, these collaborative relationships opened lines of regular communication between the college and key industry personnel regarding knowledge and skill requirements for current and future engineers. Topical areas were identified to strengthen skillset gaps as well as address emerging needs in the engineering and high-tech workforce. Research was conducted on professional requirements for licensed engineers within the State of New Mexico followed by a needs-gap analysis for possible professional development course development and/or delivery. Finally, faculty were engaged in the development and delivery of courses based on the outcomes of the needs-gap analysis and in alignment with educational expertise.

Industry partnerships were followed by partnerships with K-12 school districts. Our focus was placed on expanding existing relationships with K-12 schools, whose students currently participate in a variety of STEM outreach programs offered by the College of Engineering, to include professional development for teachers in STEM fields. Specifically, each of our STEM programs, which includes Project Lead the Way, BEST Robotics, VEX Robotics, and a PreEngineering summer immersion program, adopted common software and hardware, and professional development courses were developed to enhance knowledge of both among STEM 
teachers. Summer professional development courses offered the Project Lead the Way partnership were used to leverage additional course development and delivery in niche areas of interest.

As a Hispanic Serving Institution, we shared a commitment to educate a diverse workforce with our various partners. Collectively, we identified a need to expand student learning at the undergraduate level beyond the classroom, thus a model for pop-up professional development workshops soon followed. These workshops were developed as an outcome of our multi-year participation in the Pathways to Innovation program, which was funded by the National Science Foundation and managed by Stanford University and VentureWell to integrate innovation and entrepreneurial skills across the engineering curriculum. The Pathways program has become a champion of the pop-up model as a flexible format for enhancing student learning across multidisciplinary areas. The specific pop-up model adopted at New Mexico State University involves leveraging a combination of external partners, faculty, and engineering students (peer to peer) to deliver flexible non-credit workshops to undergraduate students to enhance their ability to work across multi-disciplinary teams. Offered as non-credit pop-up sessions, these workshops have become popular among undergraduate engineering students. These non-credit workshops provide undergraduate students with skills to readily traverse multi-disciplinary projects through venues that bridge engineering concepts and theory with application. Topics are sporadic to align with the pop-up nature of the workshops and build on a growing ecosystem for innovation and entrepreneurship. Workshops span the development of mobile Apps to project management and environmental safety.

Further expansion of the ecosystem resulted in industrial partners leading an effort to offer cocurricular non-credit design challenges to engineering students. In such challenges, faculty members work directly with an engineer from an industrial partner to create a one-day challenge that is of benefit to the industrial partner. These highly subscribed design challenges, scheduled on Saturdays, offer a hands-on professional development opportunity for engineering students. Students arrive Saturday morning, are assigned to an ad hoc team, and are presented the challenge by industry personnel. Faculty and industry are available throughout the day to serve as resources to the students. These challenges offer students an opportunity to work on a real problem and get their work reviewed by potential future colleagues in industry.

Lastly, we conducted market research to identify a fee structure for each of the professional development programs (professional engineers, K-12 teachers, undergraduate students) to ensure long-term sustainability of program development and delivery. The outcome was a balanced approach that ensured our desire for affordability and access while addressing the reality of covering direct program costs.

Our partnerships continue to grow and have contributed to an evolving and inclusive ecosystem. The resulting ecosystem allows ease of entry for the respective partners to create and deliver content based on individual interests and expertise.

Some Do's and Don'ts

Experience gained through the creation and evolution of our ecosystem has led to the adoption of best practices for maintaining I/U partnerships and sustaining the delivery of subsequent programs. Such best practices include (1) leverage existing I/U relationships to grow 
professional development courses, (2) be realistic when identifying potential partners to ensure a win-win relationship, (3) leverage faculty expertise and reputation when developing course topics, (4) maintain a pulse on evolving trends in industry workforce needs, and (5) remember your target market.

Experiences may vary and the need to follow good business practices is critical. We took note not to repeat practices that did not work and did not adopt those that we observed among other peer I/U partnerships that failed to meet the needs of our ecosystem. Some takeaways to avoid in developing a professional development I/U ecosystem include (1) don't try to force partnerships that are not a natural fit with your institution, (2) don't oversell technical expertise that does not exist within your faculty, (3) don't offer courses that compete with those offered by industry associations, (4) don't over price your courses for your target market, and (5) price your offerings to ensure that expenses are met.

\section{Evolution of a sustainable business model}

The outcome of our ecosystem has been the evolution of a sustainable business model to ensure long-term success of our I/U professional development program. Over the past three years, we have developed an administrative infrastructure to market courses, process online fee-based course registrations, and direct the various details associated with the delivery of professional development programs. The I/U program has become financially self-supportive with faculty compensated for new course development through revenue generated from fee-based courses. Where appropriate, personnel from industry partners were enlisted as advisors to ensure relevancy across the developed courses.

Policies have been developed to ensure the ethical conduct of business across the I/U relationship. Lastly, the developed courses have provided an opportunity for faculty to transfer research findings and topical expertise directly to a multi-faceted workforce in a relevant and timely manner.

\section{Program Accomplishments}

Since inception of our inclusive ecosystem, the Engineering New Mexico Resource Network has become recognized as a respected resource for the delivery of professional development courses across the state and within a multi-state region of the southwestern United States. In academic year 2014-15, our I/U partnership resulted the delivery of courses/workshops to almost 1,500 undergraduate engineering students, engineering professionals, and K-12 teachers. Examples of delivered courses/workshops include:

- Portable DE0-Nano Board FPGA Sensor Systems (engineering professionals)

- Professional Engineering: Electric Power Refresher Course (engineering professionals)

- Quality Concrete School (engineering professionals)

- Energy Efficiency in the Workplace (engineering professionals)

- Professional Development for Surveying Engineers (engineering professionals)

- Photovoltaic/National Electric Codes Training (engineering professionals)

- Advanced Manufacturing Technology Specialized Training (engineering professionals)

- Bridge Inspection Training (engineering professionals)

- Robotics programming (K-12 teacher training) 
- Project Lead the Way (K-12 teacher training)

- Development of Mobil Apps - Apple and Android based (undergraduate engineering students)

- Effective Project Management (undergraduate engineering students)

- NX Software Refresher and Certification (undergraduate engineering students)

- Environmental Safety Training Series and Certification (undergraduate engineering students)

In the current academic year we have experienced growth in both I/U partnerships and in program delivery. We currently partner with over twenty-five (25) industries and have plans to expand to include government agencies, industry associations, and other academic institutional partners.

\section{Conclusions}

Industry partnerships can be highly beneficial to colleges and universities. Sustaining such partnerships requires that clear policies and procedures be in place to mitigate any possible financial risks. The creation of the Engineering New Mexico Resource Network has provided us an organizational structure to manage our challenges and the administrative strength to create cohesive offerings with strong brand identity. Using a system of systems approach, we are moving toward our goal of a seamless value chain.

We recommend, through our own experiences that those interested in adopting a similar I/U ecosystem to examine their respective organizational setting. Essential policies and best practices need to be adopted or in place in order to forge a successful $\mathrm{I} / \mathrm{U}$ framework.

\section{Bibliography}

1. Miller, Charles (chair). A Test of Leadership: Charting the Future of U.S. Higher Education, National Commission on the Future of Higher Education in America. Washington: U.S. Department of Education, 2006.

2. Duderstadt, James J. (). Engineering for a Changing World: A Roadmap to the Future of American Engineering Practice, Research, and Education. Retrieved from http://milproj.dc.umich.edu/pdfs/2009/Engineering\%20for\%20a\%20Changing\%20World.pdf

3. Candy, P. C., and R. G. Crebert. "Ivory Tower to Concrete Jungle: The Difficult Transition from the Academy to the Workplace as Learning Environments". The Journal of Higher Education 62.5 (1991): 570-592. Retrieved from http://www.jstor.org/stable/1982209?seq=1\#page scan tab contents

4. Vest, Charles M. (July 2008). Context and Challenge for Twenty-first Century Engineering Education. Journal of Engineering Education, 235-236. Retrieved from http://www.engr.wisc.edu/services/elc/21st_Century_Engr_Educ_editorials.pdf 
5. Adams, R., R. Felder (July 2008). Reframing Professional Development: A Systems Approach to Preparing Engineering Educators to Educate Tomorrow's Engineers. The Journal of Engineering Education, 239-240.

6. Edmondson, G., Valigra, L., Kenward, M., Hudson, R., Belfield, H. (2012). Making Industry-University Partnerships Work. Science Business Innovation Board. Retrieved from http://www.sciencebusiness.net/OurReports/ReportsOverview.aspx

7. Santoro, Michael D., Betts, S.C. (2002). Making Industry-University Partnerships Work. Research Technology Management 45.3, 42-46. Retrieved from http://search.proquest.com/openview/35e7ad59554bca9aada917b35660fe37/1?pqorigsite $=$ gscholar

8. Prigge, G.W. \& Torraco, R. (2006). University-Industry Partnerships: A Study of How Top American Research Universities Establish and Maintain Successful Partnerships. Journal of Higher Education Outreach and Engagement, 2(89). Retrieved from http://openjournals.libs.uga.edu/index.php/jheoe 
